\title{
Influence of marital status on overall survival in adult patients with chordoma: a SEER-based study
}

Chao Tang ${ }^{1 \dagger}$, Ruiliang Wang ${ }^{2 \dagger}$, Qingguo $\mathrm{Lu}^{3}$, Shantao Wang ${ }^{3}$, Gen Jia ${ }^{1}$, Pengfei Cao ${ }^{1}$, Xinfa Nie ${ }^{1 *}$ and Hailong Zhang ${ }^{4^{*}}$ (D)

\begin{abstract}
Background: As a rare primary bone tumor, no studies have reported the relationship between prognosis and marital status in patients with chordoma.

Methods: We classified patients with chordoma identified from the Surveillance, Epidemiology, and End Results (SEER) database from 1975 to 2016 into four groups: married, divorced/separated, widowed, and single groups. Kaplan-Meier curves with log-rank test and Cox regression were used to analyze the effect of marital status on overall survival (OS).

Results: A total of 1080 patients were included in the study: 700 (64.8\%) were married, 88 (8.1\%) were divorced/ separated, 78 (7.2\%) were widowed, and 214 (19.8\%) were single. Among the 4 groups, the 5-year OS (45.2\%), 10year OS (12.5\%), and median OS (56.0 months) were the lowest in the widowed group. After including age, sex, primary site, marital status, disease stage, tumor size, histological type, and treatment pattern, multivariate analysis showed that marital status was still an independent risk factor for patients with chordoma, and widowed patients had the lowest OS (hazard ratio [HR] 1.71; 95\% confidence interval [CI] 1.25-2.33, $p<0.001$ ) compared with married patients. Similar results were observed after stratifying the primary site and disease stage.
\end{abstract}

Conclusion: Marital status was an independent prognostic indicator for adult patients with chordoma, and marital status was conducive to patient survival. Compared with married patients, widowed patients have a higher risk of death.

Keywords: Chordoma, Marital status, Overall survival, Prognosis, SEER

\footnotetext{
*Correspondence: 1937673829@qq.com; HLZhang301@126.com

${ }^{+}$Chao Tang and Ruiliang Wang contributed equally to this work.

'Pain Department, Pizhou City People's Hospital, Xuzhou Medical University, Xuzhou City 200032, Jiangsu Province, China

${ }^{4}$ Orthopedic Department, People's Hospital of Putuo District, Tongji University School of Medicine, Shanghai 200060, China

Full list of author information is available at the end of the article
}

(c) The Author(s). 2020 Open Access This article is licensed under a Creative Commons Attribution 4.0 International License, which permits use, sharing, adaptation, distribution and reproduction in any medium or format, as long as you give appropriate credit to the original author(s) and the source, provide a link to the Creative Commons licence, and indicate if changes were made. The images or other third party material in this article are included in the article's Creative Commons. licence, unless indicated otherwise in a credit line to the material. If material is not included in the article's Creative Commons licence and your intended use is not permitted by statutory regulation or exceeds the permitted use, you will need to obtain permission directly from the copyright holder. To view a copy of this licence, visit http://creativecommons.org/licenses/by/4.0/ The Creative Commons Public Domain Dedication waiver (http://creativecommons.org/publicdomain/zero/1.0/) applies to the data made available in this article, unless otherwise stated in a credit line to the data. 


\section{Introduction}

Chordomas are rare bone tumors that accounts for approximately $20 \%$ of primary spinal tumors and $3 \%$ of all bone tumors [1]. It is a rare and locally destructive tumor that originates from the residual tissue of the embryonic spinal cord structure and can occur anywhere along the midline bone, especially the slope of the skull base, the saddle area, and the tail of the spine [2,3]. A survey of European and American populations showed that the incidence rate of chordomas was approximately $0.08 / 100,000$, which was slightly higher in males [4]. Although chordomas grow slowly, due to their aggressive and easy metastasis, chordoma can infiltrate the surrounding bone structure [5]. Due to its high recurrence rate, which seriously affects the survival rate and the quality of life of patients, the total 5-year survival rate was only approximately $67 \%$ [6].

Many factors affect the prognosis of patients with chordoma. Previous studies have shown that surgical margin and distant metastasis were independent prognostic factors in patients with chordoma [7, 8]. In addition, patient age, histological type, and tumor size may also affect the survival of patients with chordoma $[7,9,10]$.

Marital status has always been closely related to the prognosis of cancer. Many studies have confirmed that marital status may affect the prognosis of various tumors, including osteosarcoma [11], chondrosarcoma [12], penile cancer [13], and breast cancer [14]. However, retrospective or prospective studies have not been conducted to report whether marital status affects the survival of adult patients with chordoma. Therefore, the purpose of this study was to investigate the effect of marital status on the survival of patients with chordoma according to the Surveillance, Epidemiology, and End Results (SEER) database.

\section{Materials and methods Patient selection}

The patients we studied were selected from the Surveillance Epidemiology and End Results (SEER) database funded by the National Cancer Institute. The SEER database covers approximately $28 \%$ of the USA population and includes demographic information and cancer characteristics, such as year of diagnosis, age, origin, race, insurance, marital status, primary tumor location, income status, tumor grade, disease stage, histological type, tumor-node-metastasis (TNM) stage, treatment modality, and survival time [15]. The National Cancer Institute's SEER*Stat software (version 8.3.6; SEER 18 Regs Custom Data (with additional treatment fields), November 2018 Sub (1975-2016 varying) database) was used in this study. We included 1521 patients diagnosed with chordoma between 1 January, 1975 and 31 December 2016 based on the International Classification of Diseases for Oncology (9370: chordoma, NOS; 9371: chondroid chordoma; 9372: dedifferentiated chordoma).

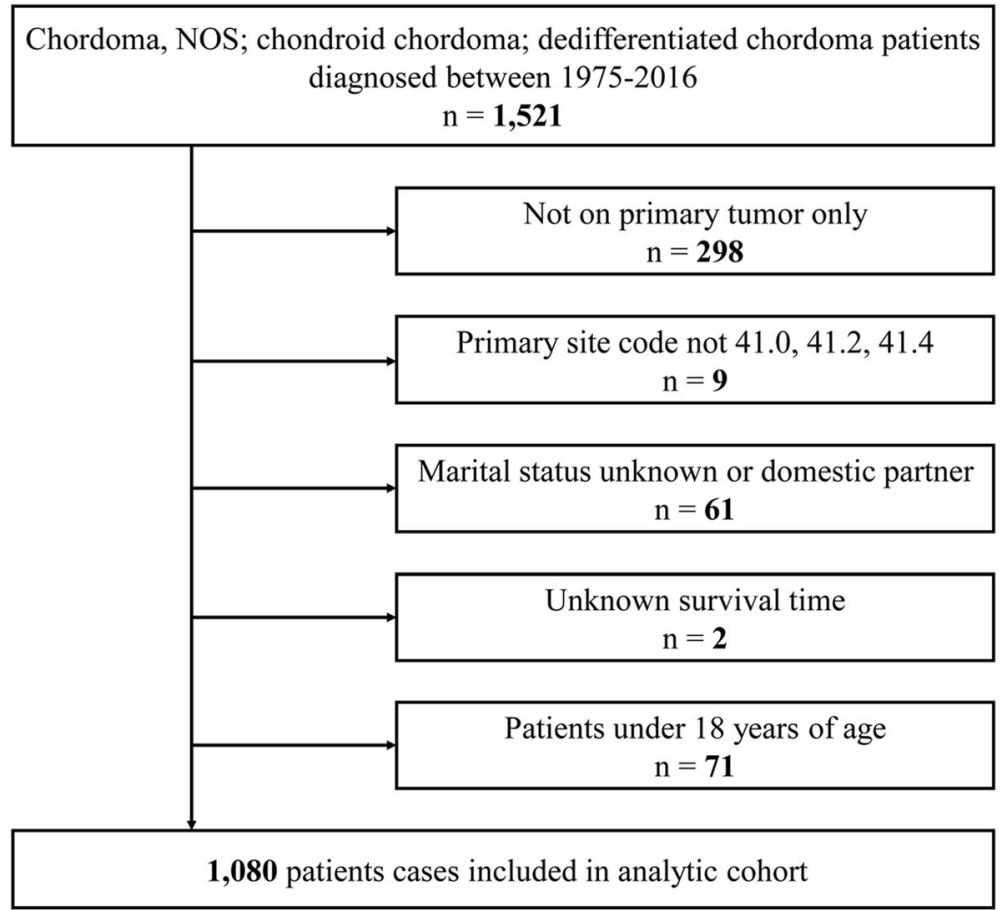

Fig. 1 Schematic flow diagram of the inclusion and exclusion criteria for our study cohort 
Table 1 Baseline demographic and clinical characteristics of chordoma patients in our study

\begin{tabular}{|c|c|c|c|c|c|c|}
\hline \multirow[t]{2}{*}{ Characteristic } & \multirow{2}{*}{$\begin{array}{l}\text { Total } \\
\text { no. (\%) }\end{array}$} & \multirow{2}{*}{$\begin{array}{l}\text { Married } \\
\text { No. (\%) }\end{array}$} & \multirow{2}{*}{$\begin{array}{l}\text { Divorced/separated } \\
\text { No. (\%) }\end{array}$} & \multirow{2}{*}{$\begin{array}{l}\text { Widowed } \\
\text { No. (\%) }\end{array}$} & \multirow{2}{*}{$\begin{array}{l}\text { Single } \\
\text { No. (\%) }\end{array}$} & \multirow[t]{2}{*}{$p$ value } \\
\hline & & & & & & \\
\hline Total & 1080 & $700(64.8)$ & $88(8.1)$ & $78(7.2)$ & $214(19.8)$ & \\
\hline Year of diagnosis & & & & & & 0.014 \\
\hline 1975-1988 & $98(9.1)$ & $70(10.0)$ & $4(4.5)$ & $12(15.4)$ & $12(5.6)$ & \\
\hline 1988-2002 & $262(24.3)$ & $181(25.9)$ & $19(21.6)$ & $20(25.6)$ & $42(19.6)$ & \\
\hline 2003-2016 & $720(66.7)$ & $449(64.1)$ & 65 (73.9) & $46(59.0)$ & $160(74.8)$ & \\
\hline Age at diagnosis & & & & & & $<0.001$ \\
\hline$<40$ & $242(22.4)$ & $131(18.7)$ & $18(20.5)$ & $0(0.0)$ & $93(43.5)$ & \\
\hline $40-60$ & $412(38.1)$ & $294(42.0)$ & $35(39.8)$ & $4(5.1)$ & 79 (36.9) & \\
\hline$>60$ & $426(39.4)$ & $275(39.3)$ & $35(39.8)$ & $74(94.9)$ & $42(19.6)$ & \\
\hline Sex & & & & & & $<0.001$ \\
\hline Male & 647 (59.9) & $441(63.4)$ & $46(52.3)$ & $21(26.9)$ & $136(63.6)$ & \\
\hline Female & $433(40.1)$ & $256(36.6)$ & $42(47.7)$ & $57(73.1)$ & $78(36.4)$ & \\
\hline Primary site & & & & & & 0.019 \\
\hline Bones of skull and face and associated joints & $436(40.4)$ & $285(40.7)$ & $34(38.6)$ & $17(21.8)$ & $100(46.7)$ & \\
\hline Vertebral column & $279(25.8)$ & $179(25.6)$ & $25(28.4)$ & $27(34.6)$ & $48(22.4)$ & \\
\hline Pelvic bone, sacrum, coccyx, and associated joints & $365(33.8)$ & $236(33.7)$ & $29(33.0)$ & $34(43.6)$ & $66(30.8)$ & \\
\hline Disease stage & & & & & & 0.587 \\
\hline Localized & $442(40.9)$ & $288(41.1)$ & $38(43.2)$ & $30(38.5)$ & $86(40.2)$ & \\
\hline Regional & $454(42.0)$ & $290(41.4)$ & $41(46.6)$ & $32(41.0)$ & $91(42.5)$ & \\
\hline Distant & $90(8.3)$ & $55(7.9)$ & $5(5.7)$ & $7(9.0)$ & $23(10.7)$ & \\
\hline Unstaged & $94(8.7)$ & $67(9.6)$ & $4(4.5)$ & $9(11.5)$ & $14(6.5)$ & \\
\hline Tumor size & & & & & & 0.084 \\
\hline$<5 \mathrm{~cm}$ & $357(33.1)$ & $229(32.7)$ & $32(36.4)$ & $18(23.1)$ & $78(36.4)$ & \\
\hline $5-10 \mathrm{~cm}$ & $256(23.7)$ & $155(22.1)$ & $21(23.9)$ & $21(26.9)$ & $59(27.6)$ & \\
\hline$>10 \mathrm{~cm}$ & $101(9.4)$ & $64(9.1)$ & $10(11.4)$ & $5(6.4)$ & $22(10.3)$ & \\
\hline Unknown & $366(33.9)$ & $252(36.0)$ & $25(28.4)$ & $34(43.6)$ & $55(25.7)$ & \\
\hline Histological type & & & & & & 0.953 \\
\hline Conventional chordoma & $1019(94.4)$ & $659(94.1)$ & $83(94.3)$ & $75(96.2)$ & $202(94.4)$ & \\
\hline Chondroid chordoma & $54(5.0)$ & $37(5.3)$ & $4(4.5)$ & $3(3.8)$ & $10(4.7)$ & \\
\hline Dedifferentiated chordoma & $7(0.6)$ & $4(0.6)$ & $1(1.1)$ & $0(0.0)$ & $2(0.9)$ & \\
\hline Surgery & & & & & & $<0.001$ \\
\hline Surgery not performed & $177(16.4)$ & $99(14.1)$ & $20(22.7)$ & $29(37.2)$ & $29(13.6)$ & \\
\hline STR & $452(41.9)$ & $295(42.1)$ & $38(43.2)$ & $23(29.5)$ & $96(44.9)$ & \\
\hline GTR & $301(27.9)$ & $199(28.4)$ & $23(26.1)$ & $12(15.4)$ & $67(31.3)$ & \\
\hline Unknown extent of resection & $150(13.9)$ & $107(15.3)$ & $7(8.0)$ & 14 (17.9) & $22(10.3)$ & \\
\hline Radiotherapy & & & & & & 0.734 \\
\hline Yes & $544(50.4)$ & $354(50.6)$ & $48(54.5)$ & $40(51.3)$ & $101(47.7)$ & \\
\hline No & $536(49.6)$ & $346(49.4)$ & $40(45.5)$ & $38(48.7)$ & $112(52.3)$ & \\
\hline Chemotherapy & & & & & & 0.639 \\
\hline Yes & $40(3.7)$ & $24(3.4)$ & $3(3.4)$ & $2(2.6)$ & $11(5.1)$ & \\
\hline No & $1040(96.3)$ & 676 (96.6) & 85 (96.6) & 76 (97.4) & 203 (94.9) & \\
\hline
\end{tabular}

Note: $p$ value $<0.05$ are shown in bold

Abbreviations: STR subtotal resection, GTR gross total/radical resection

Percentages may not total 100 because of rounding 
Table 2 Kaplan-Meier analysis overall survival for chordoma patients

\begin{tabular}{|c|c|c|c|c|c|}
\hline \multirow[t]{2}{*}{ Characteristic } & \multirow{2}{*}{$\begin{array}{l}\text { 5-year overall } \\
\text { survival, \% }\end{array}$} & \multirow{2}{*}{$\begin{array}{l}\text { 10-year overall } \\
\text { survival, } \%\end{array}$} & \multirow{2}{*}{$\begin{array}{l}\text { Median overall } \\
\text { survival (months) }\end{array}$} & \multicolumn{2}{|l|}{ Kaplan-Meier } \\
\hline & & & & Log rank $\times 2$ test & $p$ value \\
\hline Age at diagnosis & & & & 164.433 & $<0.001$ \\
\hline$<40$ & 83.8 & 74.4 & - & & \\
\hline $40-60$ & 82.8 & 58.7 & 138.0 & & \\
\hline$>60$ & 54.3 & 25.2 & 68.0 & & \\
\hline Sex & & & & 2.585 & 0.108 \\
\hline Male & 70.5 & 45.9 & 105.0 & & \\
\hline Female & 72.9 & 52.0 & 132.0 & & \\
\hline Marital status & & & & 66.240 & $<0.001$ \\
\hline Married & 73.7 & 51.5 & 125.0 & & \\
\hline Divorced/separated & 69.5 & 42.8 & 103.0 & & \\
\hline Widowed & 45.2 & 12.5 & 56.0 & & \\
\hline Single & 75.6 & 57.0 & 157.0 & & \\
\hline Primary site & & & & 41.055 & $<0.001$ \\
\hline Bones of skull and face and associated joints & 79.2 & 65.1 & 253.0 & & \\
\hline Vertebral column & 66.7 & 37.9 & 90.0 & & \\
\hline Pelvic bone, sacrum, coccyx, and associated joints & 66.4 & 40.1 & 91.0 & & \\
\hline Disease stage & & & & 29.554 & $<0.001$ \\
\hline Localized & 77.6 & 55.3 & 147.0 & & \\
\hline Regional & 71.6 & 48.2 & 105.0 & & \\
\hline Distant & 49.7 & 32.7 & 53.0 & & \\
\hline Unstaged & 65.2 & 39.0 & 89.0 & & \\
\hline Tumor size & & & & 45.181 & $<0.001$ \\
\hline$<5 \mathrm{~cm}$ & 82.3 & 70.9 & 243.0 & & \\
\hline $5-10 \mathrm{~cm}$ & 70.5 & 45.9 & 106.0 & & \\
\hline$>10 \mathrm{~cm}$ & 55.9 & 32.1 & 70.0 & & \\
\hline Unknown & 67.0 & 41.0 & 94.0 & & \\
\hline Histological type & & & & 12.265 & 0.002 \\
\hline Conventional chordoma & 71.5 & 47.6 & 110.0 & & \\
\hline Chondroid chordoma & 76.6 & 72.8 & - & & \\
\hline Dedifferentiated chordoma & 28.6 & 28.6 & 14.0 & & \\
\hline Surgery & & & & 97.790 & $<0.001$ \\
\hline Surgery not performed & 48.3 & 26.0 & 56.0 & & \\
\hline STR & 78.1 & 58.5 & 154.0 & & \\
\hline GTR & 82.9 & 59.3 & 178.0 & & \\
\hline Unknown extent of resection & 59.1 & 31.9 & 80.0 & & \\
\hline Radiotherapy & & & & 0.140 & 0.708 \\
\hline Yes & 72.7 & 47.1 & 106.0 & & \\
\hline No & 70.0 & 49.7 & 120.0 & & \\
\hline Chemotherapy & & & & 11.445 & 0.001 \\
\hline Yes & 47.9 & 28.1 & 51.0 & & \\
\hline No & 72.4 & 49.4 & 119.0 & & \\
\hline
\end{tabular}

Note: $p$ value $<0.05$ are shown in bold

Abbreviations: STR subtotal resection, GTR gross total/radical resection 


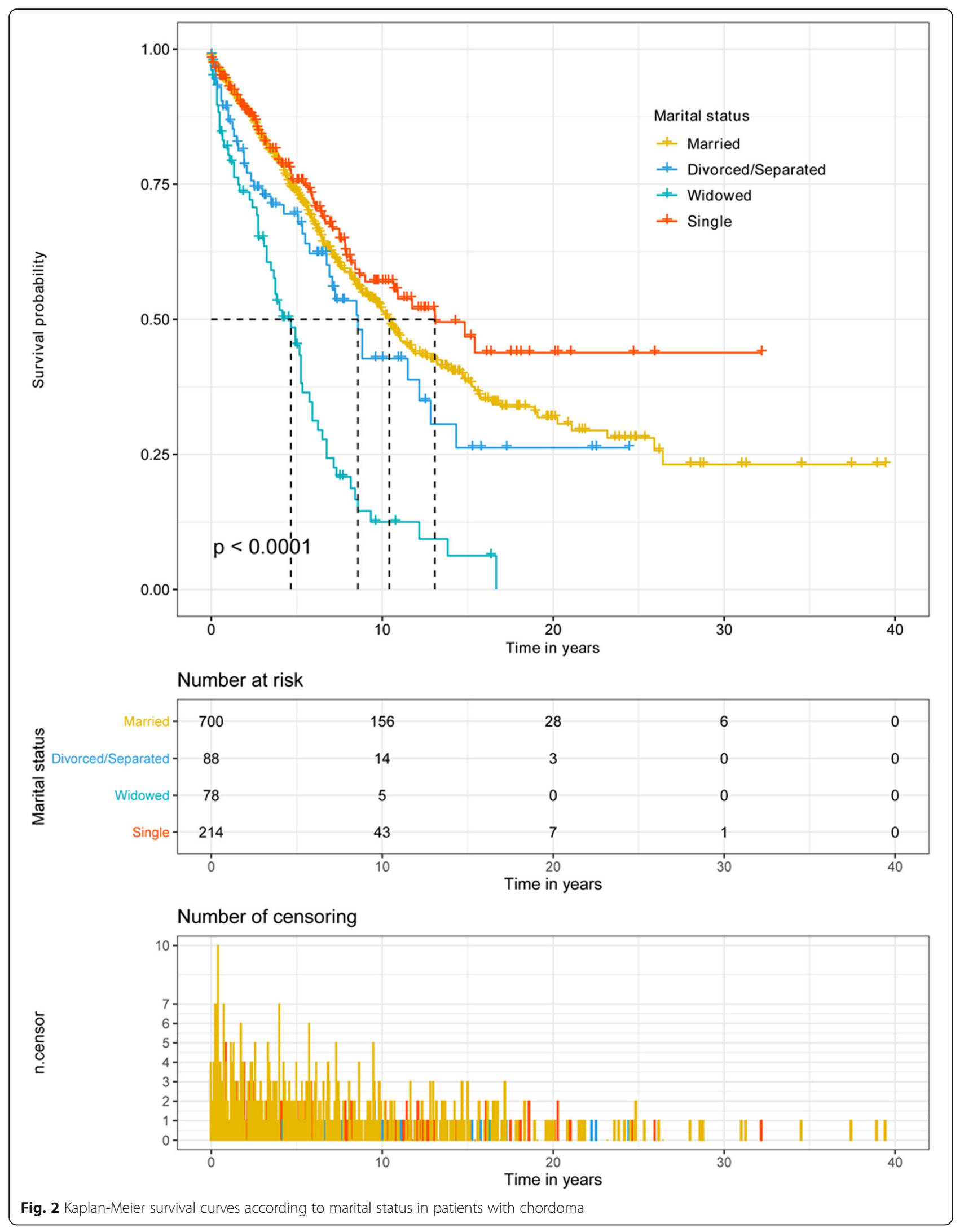


The exclusion criteria were as follows: (a) not one primary tumor only $(n=298)$; (b) primary site code not 41.0, 41.2, or 41.4 $(n=9)$; (c) marital status unknown or domestic partner $(n=61)$; (d) unknown survival time ( $n$ $=2)$; and (e) patients under 18 years of age $(n=71)$. Finally, based on the above screening criteria, we were left with 1080 eligible patients diagnosed with chordoma.

\section{Study variables}

Variable definition information about year of diagnosis, age at diagnosis, sex, primary site, marital status, disease stage, tumor size, histological type, treatment pattern (surgery [16], radiotherapy, chemotherapy), and survival time can be found in the SEER database. The starting point of the follow-up was the date of diagnosis of chordoma. The overall survival (OS) time is the length of time from the date of diagnosis to the end of the patient's follow-up or death.

\section{Statistical analysis}

Chi-square analysis was performed to evaluate the clinical characteristics of the four marital statuses in patients

Table 3 Kaplan-Meier analysis overall survival for chordoma patients based on primary site and disease stage

\begin{tabular}{|c|c|c|c|c|c|}
\hline \multirow[t]{2}{*}{ Characteristic } & \multirow{2}{*}{$\begin{array}{l}5 \text {-year overall } \\
\text { survival, } \%\end{array}$} & \multirow{2}{*}{$\begin{array}{l}\text { 10-year overall } \\
\text { survival, } \%\end{array}$} & \multirow{2}{*}{$\begin{array}{l}\text { Median overall } \\
\text { survival (months) }\end{array}$} & \multicolumn{2}{|l|}{ Kaplan-Meier } \\
\hline & & & & Log rank $\times 2$ test & $p$ value \\
\hline Primary site & & & & 35.462 & $<0.001$ \\
\hline \multicolumn{6}{|l|}{ Bones of skull and face and associated joints } \\
\hline Married & 81.0 & 68.3 & 253.0 & & \\
\hline Divorced/separated & 65.8 & 44.9 & 106.0 & & \\
\hline Widowed & 45.3 & 18.1 & 42.0 & & \\
\hline Single & 85.0 & 71.8 & - & & \\
\hline Vertebral column & & & & 38.754 & $<0.001$ \\
\hline Married & 68.2 & 38.9 & 97.0 & & \\
\hline Divorced/separated & 82.8 & 40.9 & 102.0 & & \\
\hline Widowed & 32.5 & 0.0 & 33.0 & & \\
\hline Single & 74.1 & 58.3 & 141.0 & & \\
\hline Pelvic bone, sacrum, coccyx, and associated joints & & & & 7.278 & 0.064 \\
\hline Married & 69.6 & 44.9 & 106.0 & & \\
\hline Divorced/separated & 62.6 & 45.0 & 81.0 & & \\
\hline Widowed & 54.7 & 19.6 & 63.0 & & \\
\hline Single & 63.1 & 32.4 & 80.0 & & \\
\hline \multicolumn{6}{|l|}{ Disease stage } \\
\hline Localized & & & & 33.341 & $<0.001$ \\
\hline Married & 78.1 & 57.8 & 166.0 & & \\
\hline Divorced/separated & 78.5 & 58.5 & 146.0 & & \\
\hline Widowed & 47.0 & 10.4 & 59.0 & & \\
\hline Single & 87.2 & 65.8 & 178.0 & & \\
\hline Regional & & & & 31.648 & $<0.001$ \\
\hline Married & 74.4 & 50.3 & 121.0 & & \\
\hline Divorced/separated & 68.4 & 40.7 & 87.0 & & \\
\hline Widowed & 40.0 & 13.3 & 46.0 & & \\
\hline Single & 76.5 & 59.7 & - & & \\
\hline Distant & & & & 17.771 & $<0.001$ \\
\hline Married & 59.4 & 39.9 & 80.0 & & \\
\hline Divorced/separated & 0.0 & 0.0 & 12.0 & & \\
\hline Widowed & 28.6 & 0.0 & 16.0 & & \\
\hline Single & 42.3 & 30.2 & 32.0 & & \\
\hline
\end{tabular}


with chordoma. Kaplan-Meier curves were used to estimate the factors related to the OS, 5-year OS, and 10year OS of patients with chordoma, and the log-rank test was used to analyze the difference between the curves. Univariate and multivariate Cox regression models were performed to estimate the hazard ratios (HRs) and 95\% confidence intervals (CIs) to analyze independent prognostic factors associated with patients with chordoma. All statistical analyses used Statistical Package for the Social Sciences software (version 24.0; SPSS, Chicago, USA) and R version 3.5.3 (R Foundation for Statistical Computing, http://www.r-project.org/). The Survminer package included in Kaplan-Meier analysis with log-rank testing was applied to conduct the survival data analysis and visualization (Drawing Survival Curves using 'ggplot2' [R package survminer version 0.2.0]). Univariate
Cox proportional hazards regression and multivariate Cox proportional hazards regression with the Wald test were performed to determine risk factors associated with overall mortality and cancer-specific mortality. Statistical significance was considered when the $p$ value is $\leq 0.05$ (both sides).

\section{Results}

Demographic and clinicopathologic characteristics of patients with chordoma

According to the inclusion and exclusion criteria in Fig. 1, our study included a total of 1080 eligible patients with chordoma from 1975 to 2017. The number of married, divorced/separated, widowed, and single group were 700 (64.8\%), 88 (8.1\%), 78 (7.2\%), and 214 (19.8\%), respectively. Table 1 shows the clinical characteristics and demographic

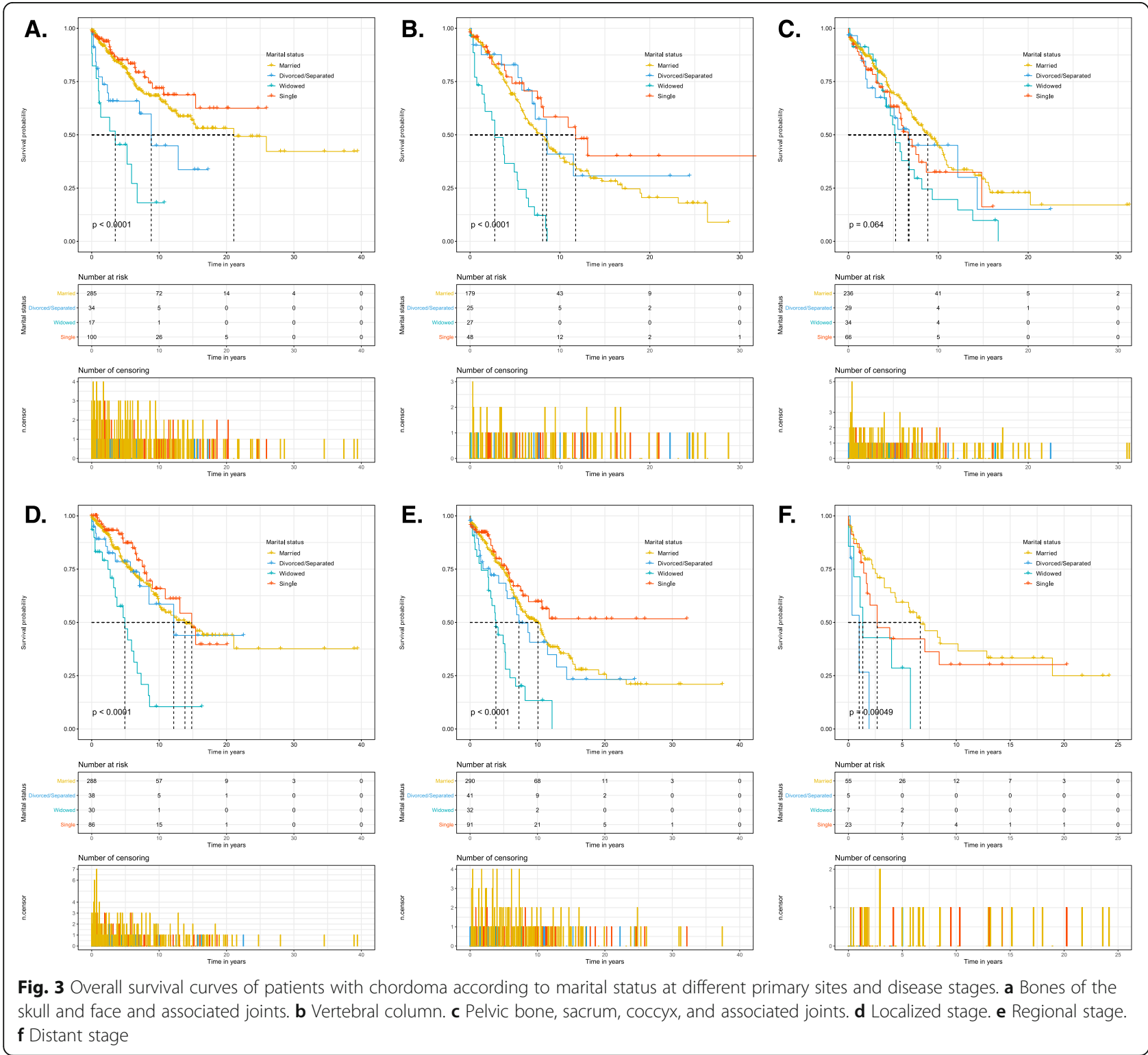


Table 4 Univariate and multivariate analysis of overall survival rates

\begin{tabular}{|c|c|c|c|c|}
\hline \multirow[t]{2}{*}{ Characteristic } & \multicolumn{2}{|l|}{ Univariate analysis } & \multicolumn{2}{|l|}{$\underline{\text { Multivariate analysis }}$} \\
\hline & Hazard ratio $(95 \% \mathrm{Cl})$ & $p$ value & Hazard ratio $(95 \% \mathrm{Cl})$ & $p$ value \\
\hline Age at diagnosis & & $<0.001$ & & $<0.001$ \\
\hline$<40$ & Reference & & Reference & \\
\hline $40-60$ & $1.92(1.40-2.64)$ & $<0.001$ & $1.97(1.42-2.73)$ & $<0.001$ \\
\hline$>60$ & $4.83(3.57-6.53)$ & $<0.001$ & $4.28(3.08-5.96)$ & $<0.001$ \\
\hline \multicolumn{5}{|l|}{ Sex } \\
\hline Male & Reference & & Reference & \\
\hline Female & $0.86(0.71-1.04)$ & 0.109 & $0.82(0.67-1.00)$ & 0.048 \\
\hline Marital status & & $<0.001$ & & 0.006 \\
\hline Married & Reference & & Reference & \\
\hline Divorced/separated & $1.29(0.92-1.80)$ & 0.136 & $1.42(1.01-1.99)$ & 0.046 \\
\hline Widowed & $2.82(2.13-3.73)$ & $<0.001$ & $1.71(1.25-2.33)$ & $<0.001$ \\
\hline Single & $0.83(0.64-1.09)$ & 0.175 & $1.16(0.88-1.53)$ & 0.303 \\
\hline Primary site & & $<0.001$ & & 0.181 \\
\hline Bones of skull and face and associated joints & Reference & & Reference & \\
\hline Vertebral column & $1.93(1.52-2.44)$ & $<0.001$ & $1.19(0.92-1.54)$ & 0.196 \\
\hline Pelvic bone, sacrum, coccyx, and associated joints & $1.94(1.54-2.44)$ & $<0.001$ & $0.97(0.73-1.28)$ & 0.809 \\
\hline Disease stage & & $<0.001$ & & $<0.001$ \\
\hline Localized & Reference & & Reference & \\
\hline Regional & $1.41(1.13-1.75)$ & 0.002 & $1.43(1.15-1.79)$ & 0.002 \\
\hline Distant & $2.22(1.62-3.05)$ & $<0.001$ & $2.31(1.66-3.20)$ & $<0.001$ \\
\hline Unstaged & $1.68(1.24-2.29)$ & 0.001 & $1.17(0.85-1.62)$ & 0.327 \\
\hline Tumor size & & $<0.001$ & & $<0.001$ \\
\hline$<5 \mathrm{~cm}$ & Reference & & Reference & \\
\hline $5-10 \mathrm{~cm}$ & $1.96(1.47-2.61)$ & $<0.001$ & $1.25(0.91-1.71)$ & 0.173 \\
\hline$>10 \mathrm{~cm}$ & $2.98(2.08-4.27)$ & $<0.001$ & $1.85(1.22-2.80)$ & 0.004 \\
\hline Unknown & $2.04(1.57-2.65)$ & $<0.001$ & $1.50(1.13-1.98)$ & 0.005 \\
\hline Histological type & & 0.004 & & 0.124 \\
\hline Conventional chordoma & Reference & & Reference & \\
\hline Chondroid chordoma & $0.52(0.29-0.92)$ & 0.025 & $0.78(0.43-1.42)$ & 0.419 \\
\hline Dedifferentiated chordoma & $3.03(1.25-7.32)$ & 0.014 & $2.11(0.83-5.35)$ & 0.115 \\
\hline Surgery & & $<0.001$ & & $<0.001$ \\
\hline Surgery not performed & Reference & & Reference & \\
\hline STR & $0.39(0.30-0.52)$ & $<0.001$ & $0.58(0.44-0.76)$ & $<0.001$ \\
\hline GTR & $0.35(0.26-0.46)$ & $<0.001$ & $0.41(0.30-0.55)$ & $<0.001$ \\
\hline Unknown extent of resection & $0.82(0.63-1.07)$ & 0.144 & $0.95(0.71-1.26)$ & 0.723 \\
\hline \multicolumn{5}{|l|}{ Radiotherapy } \\
\hline Yes & Reference & & Reference & \\
\hline No & $0.97(0.80-1.16)$ & 0.709 & $1.07(0.89-1.30)$ & 0.466 \\
\hline \multicolumn{5}{|l|}{ Chemotherapy } \\
\hline Yes & Reference & & Reference & \\
\hline No & $0.51(0.34-0.76)$ & 0.001 & $0.71(0.47-1.09)$ & 0.120 \\
\hline
\end{tabular}

Abbreviations: STR subtotal resection, GTR gross total/radical resection 
of all adult patients with chordoma. The chi-square test showed that there were significant differences in the five variables of diagnosis year $(p=0.014)$, age at diagnosis $(p<$ $0.001)$, sex $(p<0.001)$, primary site $(p=0.019)$, and surgery $(p<0.001)$. With the increase in years, the proportion of patients with chordoma also increased. In the whole cohort, the majority of patients were male (59.9\%), the primary site was bones of the skull and face and associated joints $(40.4 \%)$, and localized stage predominated (40.9\%). In addition, the percentages of older ( $>60$ years, $94.9 \%$ ), female (73.1\%), and non-surgery (37.2\%) patients in the widowed group were also the highest.

\section{Survival of patients with chordoma}

By analyzing the Kaplan-Meier curve with a log-rank test, we found that age at diagnosis $(p<0.001)$, marital status ( $p$ $<0.001)$, primary site $(p<0.001)$, disease stage $(p<0.001)$, tumor size $(p<0.001)$, histological type $(p=0.002)$, surgery $(p<0.001)$, and chemotherapy $(p=0.001)$ were associated with OS (Table 2). The 5-year OS and 10-year OS of married, divorced/separated, widowed, and single patients were $73.7 \%$ and $51.5 \%, 69.5 \%$ and $42.8 \%, 45.2 \%$ and $12.5 \%$, and $75.6 \%$ and $57.0 \%$, respectively, and the median survival times of married, divorced/separated, widowed, and single patients were 125.0 months, 103.0 months, 56.0 months, and 157.0 months, respectively (Fig. 2). Widowed patients had the lowest 5-year OS, 10-year OS, and median overall survival time, while single patients had the highest 5-year OS, 10-year OS, and median overall survival time. After stratifying the primary site and disease stage, we still observed similar results (Table 3 and Fig. 3).

\section{Identification of prognostic factors of the OS of patients with chordoma}

Univariate and multivariate Cox regression were used to analyze the prognostic factors associated with the OS of

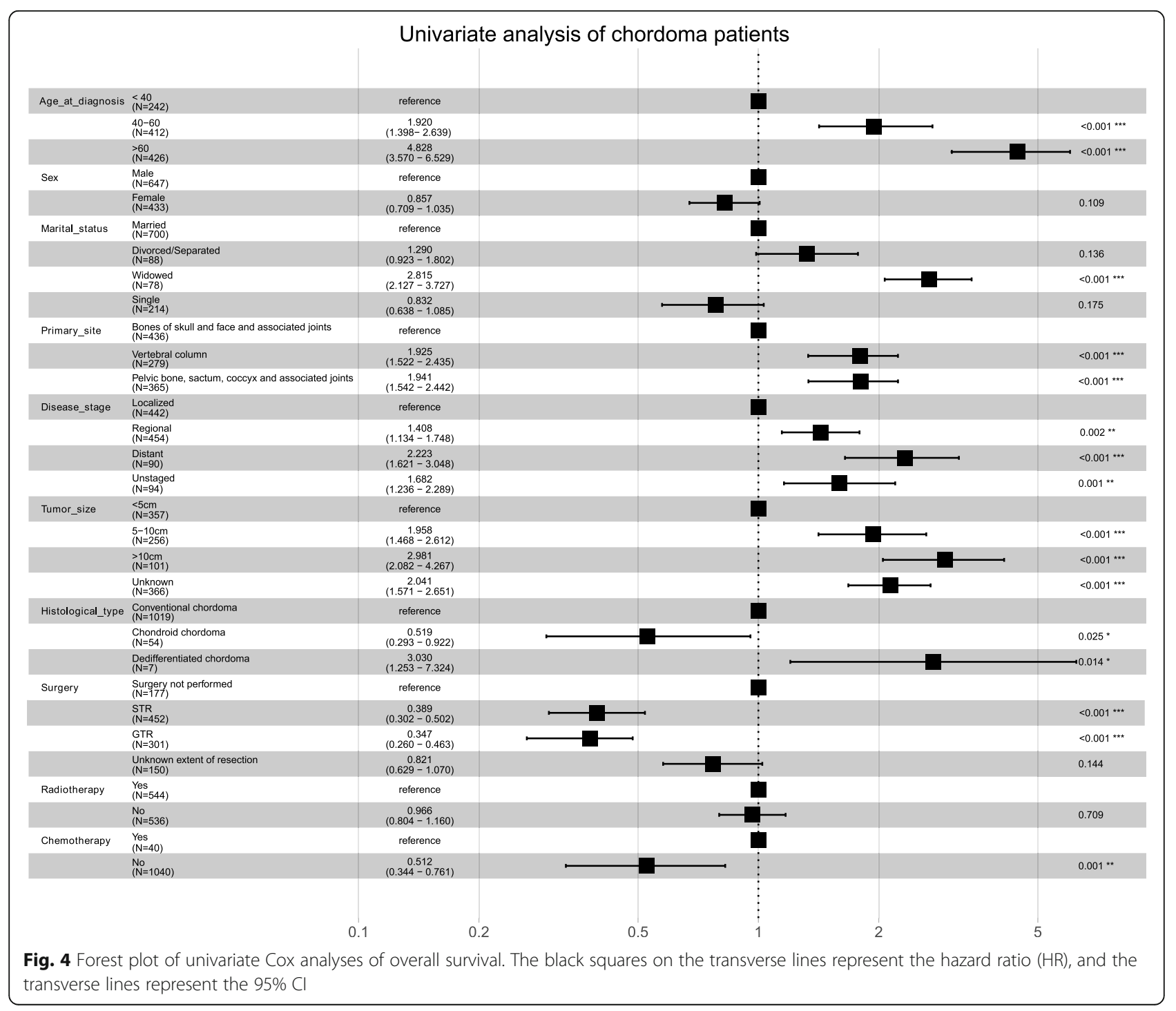


patients with chordoma (Table 4). Univariate Cox regression analysis showed that age at diagnosis, marital status, primary site, disease stage, tumor size, histological type, surgery, and chemotherapy were factors (all $p<0.05$ ) related to OS in patients with chordoma (Fig. 4). Moreover, after all factors were included in the multivariate analysis, primary site, histological type, radiotherapy, and chemotherapy were not independent risk factors for patients with chordoma (Fig. 5). In addition, multivariate analysis showed that widowed patients had the worst OS (HR 1.71; 95\% CI $1.25-2.33, p<0.001)$ compared with married patients.

In the stratification of primary site and disease stages (Table 5), univariate analysis showed that marital status was a risk factor for OS in the primary site of "bones of the skull and face and associated joints," "vertebral column," and "localized," "regional," and "distant" disease stages. In addition, multivariate analysis showed that marital status was an independent risk factor for the primary site of "bones of skull and face and associated joints" and "vertebral column." Moreover, although marital status was not an independent risk factor for the prognosis of patients with chordoma at the disease stages of "localized," "regional," and "distant," widowed patients were at higher risk of survival compared with married, divorced/separated, or single patients.

\section{Discussion}

In this 42-year retrospective study, we conducted univariate and multivariate Cox regression analysis of a large number of adult patients with chordoma through the SEER database. We found that marital status was an independent risk factor for OS in adult patients with chordoma, and marital status had a protective effect on the survival outcome of adult patients with chordoma.

Marital status is widely considered to be an independent prognostic factor for many malignancies [17-20]. However,

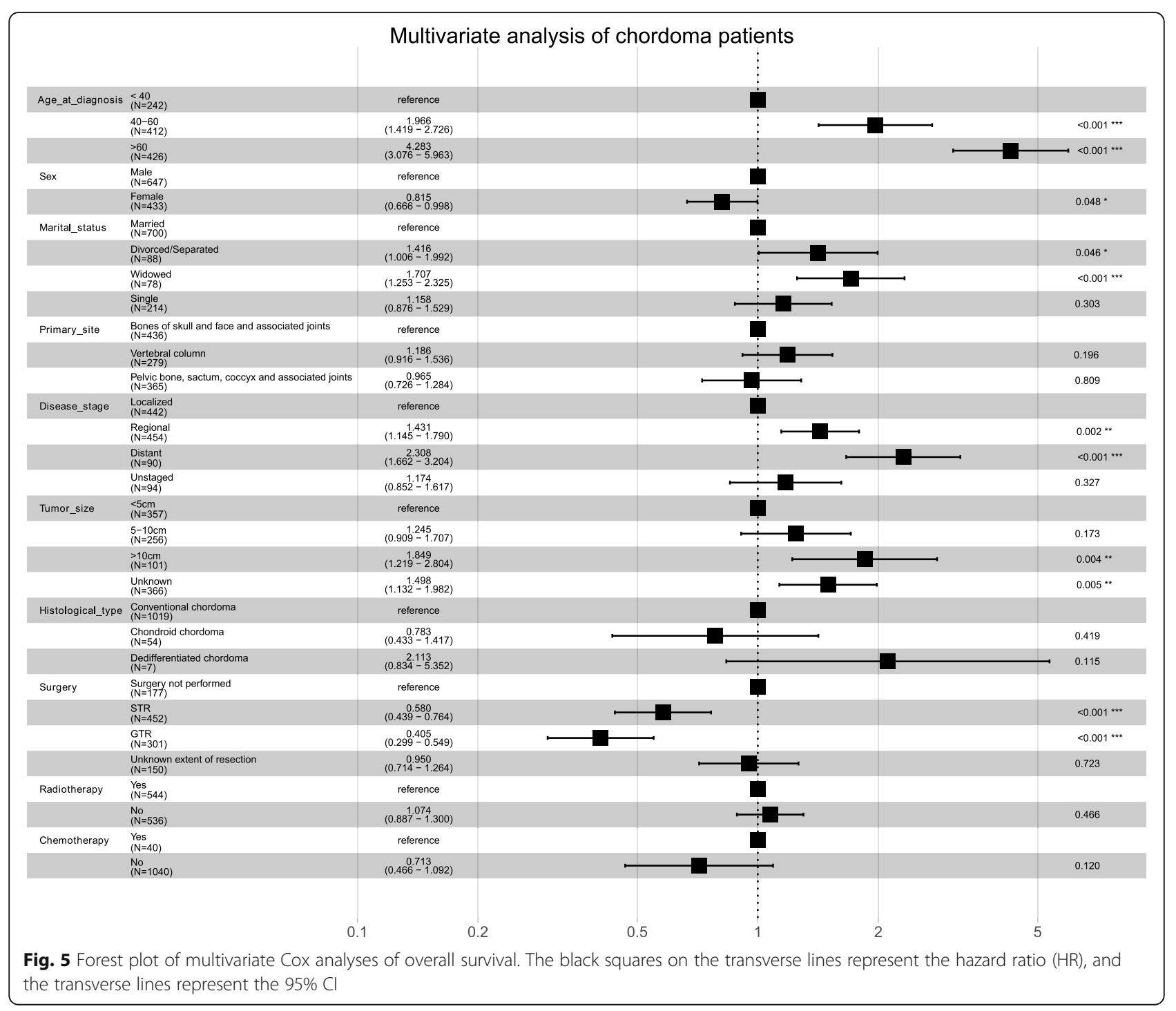


Table 5 Univariate and multivariate analysis of overall survival rates based on primary site and disease stage

\begin{tabular}{|c|c|c|c|c|}
\hline \multirow[t]{2}{*}{ Characteristic } & \multicolumn{2}{|l|}{ Univariate analysis } & \multicolumn{2}{|l|}{ Multivariate analysis } \\
\hline & Hazard ratio $(95 \% \mathrm{Cl})$ & $p$ value & Hazard ratio $(95 \% \mathrm{Cl})$ & $p$ value \\
\hline \multicolumn{5}{|l|}{ Primary site } \\
\hline Bones of skull and face and associated joints & & $<0.001$ & & 0.017 \\
\hline Married & Reference & & Reference & \\
\hline Divorced/separated & $2.01(1.14-3.56)$ & 0.016 & $2.31(1.26-4.22)$ & 0.007 \\
\hline Widowed & $4.33(2.35-8.00)$ & $<0.001$ & $2.34(1.18-4.65)$ & 0.015 \\
\hline Single & $0.74(0.45-1.21)$ & 0.233 & $1.15(0.67-1.95)$ & 0.618 \\
\hline Vertebral column & & $<0.001$ & & 0.011 \\
\hline Married & Reference & & Reference & \\
\hline Divorced/separated & $0.81(0.44-1.51)$ & 0.514 & $0.94(0.48-1.86)$ & 0.863 \\
\hline Widowed & $3.33(2.11-5.26)$ & $<0.001$ & $2.43(1.44-4.12)$ & 0.001 \\
\hline Single & $0.66(0.39-1.10)$ & 0.111 & $0.82(0.48-1.43)$ & 0.488 \\
\hline Pelvic bone, sacrum, coccyx, and associated joints & & 0.064 & & 0.277 \\
\hline Married & Reference & & Reference & \\
\hline Divorced/separated & $1.26(0.72-2.19)$ & 0.423 & $1.24(0.69-2.25)$ & 0.477 \\
\hline Widowed & $1.74(1.12-2.71)$ & 0.014 & $0.96(0.57-1.60)$ & 0.867 \\
\hline Single & $1.36(0.90-2.05)$ & 0.140 & $1.54(0.99-2.38)$ & 0.056 \\
\hline \multicolumn{5}{|l|}{ Disease stage } \\
\hline Localized & & $<0.001$ & & 0.483 \\
\hline Married & Reference & & Reference & \\
\hline Divorced/separated & $1.15(0.62-2.17)$ & 0.655 & $1.17(0.60-2.29)$ & 0.650 \\
\hline Widowed & $3.54(2.16-5.80)$ & $<0.001$ & $1.54(0.89-2.67)$ & 0.126 \\
\hline Single & $0.79(0.48-1.29)$ & 0.340 & $1.20(0.70-2.06)$ & 0.519 \\
\hline Regional & & $<0.001$ & & 0.055 \\
\hline Married & Reference & & Reference & \\
\hline Divorced/separated & $1.22(0.77-1.93)$ & 0.401 & $1.31(0.81-2.11)$ & 0.266 \\
\hline Widowed & $2.80(1.82-4.32)$ & $<0.001$ & $1.95(1.23-3.10)$ & 0.005 \\
\hline Single & $0.69(0.45-1.04)$ & 0.073 & $1.09(0.71-1.67)$ & 0.702 \\
\hline Distant & & $<0.001$ & & 0.159 \\
\hline Married & Reference & & Reference & \\
\hline Divorced/separated & $6.83(2.25-20.73)$ & 0.001 & $4.43(1.19-16.53)$ & 0.027 \\
\hline Widowed & $2.78(1.14-6.80)$ & 0.025 & $3.14(0.71-13.99)$ & 0.133 \\
\hline Single & $1.31(0.69-2.48)$ & 0.405 & $1.33(0.58-3.04)$ & 0.497 \\
\hline
\end{tabular}

the effect of marital status on adult patients with chordoma has not been fully investigated. In this study, we first explored the effect of marital status on the OS of adult patients with chordoma, and we found that married patients had better OS than divorced/separated and widowed patients. In multivariate analysis, after adjusting for diagnosis age, sex, marital status, primary site, disease stage, histological type, tumor size, surgery, radiotherapy, and chemotherapy, marital status was still a risk factor for patients with chordoma. The widowed group patients had the highest risk ratio (HR 1.71; 95\% CI 1.25-2.33, $p<0.001$ ), and the benefits of married patients remained. Compared with the married, divorced/ separated, or single groups, widowed patients had the worst 5-year OS (45.2\%), 10-year OS (12.5\%), and median survival time (56.0 months). Similar results were observed in the subgroup analysis of primary site and disease stages.

The effect of marital status on the survival of patients with chordoma has been studied before. Pan et al. [8] analyzed 808 patients with primary spinal chordoma from 1973 to 2014 and found that marital status was not the main factor affecting OS. Huang et al. [16] also showed that marital status was not a prognostic factor for patients with primary spinal chordoma. In our study, we included chordoma in the skull base, excluded all 
patients younger than 18 years old, and divided patients into four groups (married group, divorced/separated group, widowed group, and single group). It was found that marital status was an independent prognostic factor for adult patients with chordoma, which reduced the bias in case selection.

In our study, we found that the proportion of patients over 60 years old in the widowed group was as high as $94.9 \%$, which was significantly higher than that in the married, divorced/separated and single groups. Elderly patients are more likely to die due to their poor physical quality and greater complications [21], which may be an important reason for the low survival rate of the widowed group. In addition, we also found that women accounted for the highest proportion (73.1\%) of the widowed group. The activity of natural killer cells (NKs) plays an important role in the defense against tumors and virus infection. Studies have shown that bereaved women showed a decrease in NK activity and an increase in plasma cortisol levels compared with the control group, which may also lead to an increase in mortality in widowed patients [22].

In addition, the widowed group had the highest (37.2\%) rate of non-surgery, and inadequate treatment may also lead to deterioration of the prognosis of the widowed group [23]. Moreover, widowed patients have an increased risk of stress and mental illness due to the lack of a partner [24]. In contrast, married patients have better family conditions and can receive more social support from their spouses and families [25]. Good marital status can help reduce anxiety, stress, and negative emotions and provide more material help. Studies have shown that negative emotions can lead to longer infection times and longer wound healing [26].

There are limitations to be recognized in this study. First, this study was a retrospective study with inevitable selection bias. Second, the SEER database only records marital status at the time of diagnosis, but it does not report whether the subsequent marital status has changed. This change will also affect the survival of patients and confuse the differences in survival outcomes based on marital status. In addition, the specific details regarding radiotherapy and chemotherapy were not included, such as the specific regimen of chemotherapy or the dose, fractionation, and beam energy of radiotherapy, which may also be prognostic factors for patients with chordoma.

\section{Conclusions}

Our study found that marital status was an independent prognostic indicator for adult patients with chordoma and that marital status was conducive to patient survival. Widowed patients had worse OS than the other groups of patients, and similar results were observed in the subgroup analysis.

\section{Abbreviations}

SEER: Surveillance, Epidemiology and End Results; OS: Overall survival; CT: Chemotherapy; RT: Radiotherapy; HR: Hazard ratios; Cl: Confidence interval; TNM: Tumor-node-metastasis

\section{Acknowledgements}

We would like to thank the staff of the National Cancer Institute and their colleagues across the USA and those at Information Management Services, Inc., who have been involved with the Surveillance, Epidemiology and End Results (SEER) Program.

\section{Authors' contributions}

$C T, X N$, and $H Z$ studied the concept and design. CT, RW, and QL collected the data. CT, SW, GJ, and PC analyzed and interpreted the data. CT and RW drafted the manuscript. XN and $\mathrm{HZ}$ critically revised the manuscript for important intellectual content. CT and RW performed the statistical analysis. The author(s) read and approved the final manuscript.

\section{Funding}

This work was supported by grants from Shanghai Municipal Commission of Health and Family Planning (no. 03.02.17.008) to Hailong Zhang.

\section{Availability of data and materials}

The datasets generated for this study are available on request to the corresponding author

Ethics approval and consent to participate

This article does not contain any studies with human participants or animals performed by any of the authors.

Consent for publication

Not applicable.

\section{Competing interests}

We declare that there are no conflicts of interest between authors.

\section{Author details}

${ }^{1}$ Pain Department, Pizhou City People's Hospital, Xuzhou Medical University, Xuzhou City 200032, Jiangsu Province, China. ${ }^{2}$ Nursing Department, Xijing Hospital, Air Force Medical University, Xi'an City 710032, Shanxi Province, China. ${ }^{3}$ Trauma Center, Pizhou City People's Hospital, Xuzhou Medical University, Xuzhou City 200032, Jiangsu Province, China. ${ }^{4}$ Orthopedic Department, People's Hospital of Putuo District, Tongji University School of Medicine, Shanghai 200060, China.

Received: 19 February 2020 Accepted: 14 July 2020

Published online: 23 July 2020

\section{References}

1. Grosche S, Hubschmann D, Raimondi F, Horak P, Warsow G, Frohlich M, et al. Defective homologous recombination DNA repair as therapeutic target in advanced chordoma. Nat Commun. 2019;10.

2. McMaster ML, Goldstein AM, Bromley CM, Ishibe N, Parry DM. Chordoma: incidence and survival patterns in the United States, 1973-1995. Cancer Cause Control. 2001;12(1):1-11.

3. Hung GY, Horng JL, Yen HJ, Yen CC, Chen WM, Chen PCH, et al. Incidence patterns of primary bone cancer in Taiwan (2003-2010): A Population-Based Study. Annals of Surgical Oncology. 2014;21(8):2490-8.

4. Smoll NR, Gautschi OP, Radovanovic I, Schaller K, Weber DC. Incidence and relative survival of chordomas The Standardized Mortality Ratio and the Impact of Chordomas on a Population. Cancer. 2013;119(11):2029-37.

5. Al-Mefty O. Chordoma. Acta Neurochir. 2017;159(10):1869-71.

6. Bergh P, Kindblom LG, Gunterberg B, Remotti F, Ryd W, Meis-Kindblom JM. Prognostic factors in chordoma of the sacrum and mobile spine - A study of 39 patients. Cancer. 2000;88(9):2122-34.

7. Lee IJ, Lee RJ, Fahim DK. Prognostic factors and survival outcome in patients with chordoma in the United States: a population-based analysis. World Neurosurg. 2017;104:346-55.

8. Pan Y, Lu LY, Chen JQ, Zhong Y, Dai ZH. Analysis of prognostic factors for survival in patients with primary spinal chordoma using the SEER Registry from 1973 to 2014. J Orthop Surg Res. 2018;13. 
9. Thieblemont C, Biron P, Rocher F, Bouhour D, Bobin JY, Gerard JP, et al. Prognostic factors in chordoma: role of postoperative radiotherapy. Eur $\rfloor$ Cancer. 1995;31A(13-14):2255-9.

10. al-Mefty O, Borba LA. Skull base chordomas: a management challenge. J Neurosurg. 1997;86(2):182-9.

11. Qiu S, Tao L, Zhu Y. Marital status and survival in osteosarcoma patients: an analysis of the Surveillance, Epidemiology, and End Results (SEER) Database. Med Sci Monitor. 2019;25:8190-203.

12. Gao ZY, Ren FG, Song H, Wang YQ, Wang YB, Gao ZC, et al. Marital status and survival of patients with chondrosarcoma: a population-based analysis. Med Sci Monitor. 2018;24:6638-48.

13. Mao W, Zhang Z, Huang X, Fan J, Geng J. Marital status and survival in patients with penile cancer. J Cancer. 2019;10(12):2661-9.

14. Hinyard L, Wirth LS, Clancy JM, Schwartz T. The effect of marital status on breast cancer-related outcomes in women under 65: A SEER database analysis. Breast. 2017;32:13-7.

15. Mao WP, Deng F, Wang DY, Gao L, Shi XQ. Treatment of advanced gallbladder cancer: A SEER-based study. Cancer Med-Us. 2020;9(1):141-50.

16. Huang JF, Chen D, Sang CM, Zheng XQ, Lin JL, Lin Y, et al. Nomogram for individualized prediction and prognostic factors for survival in patients with primary spinal chordoma: a population-based longitudinal cohort study. World Neurosurg. 2019:128:E603-E14.

17. Sergesketter AR, Thomas SM, Lane WO, Shammas RL, Greenup RA, Hollenbeck ST. The influence of marital status on contemporary patterns of postmastectomy breast reconstruction. J Plast Reconstr Aesthet Surg. 2019; 72(5):795-804

18. Zhang SL, Wang WR, Liu ZJ, Wang ZM. Marital status and survival in patients with soft tissue sarcoma: a population-based, propensity-matched study. Cancer Med. 2019;8(2):465-79.

19. Feng Y, Dai W, Li Y, Mo S, Li Q, Cai S. The effect of marital status by age on patients with colorectal cancer over the past decades: a SEER-based analysis. Int J Colorectal Dis. 2018;33(8):1001-10.

20. Niu Q, Lu Y, Wu Y, Xu S, Shi Q, Huang T, et al. The effect of marital status on the survival of patients with bladder urothelial carcinoma: A SEER database analysis. Medicine (Baltimore). 2018;97(29):e11378.

21. Ge LX, Mordiffi SZ. Factors associated with higher caregiver burden among family caregivers of elderly cancer patients a systematic review. Cancer Nurs. 2017;40(6):471-8.

22. Irwin M, Daniels M, Risch SC, Bloom E, Weiner H. Plasma cortisol and natural killer cell activity during bereavement. Biol Psychiatry. 1988;24(2):173-8.

23. Zhai Z, Zhang F, Zheng Y, Zhou L, Tian T, Lin S, et al. Effects of marital status on breast cancer survival by age, race, and hormone receptor status: a population-based Study. Cancer Med. 2019;8(10):4906-17.

24. Kaiser NC, Hartoonian N, Owen JE. Toward a cancer-specific model of psychological distress: population data from the 2003-2005 National Health Interview Surveys. J Cancer Surviv. 2010;4(4):291-302

25. Aizer AA, Chen MH, McCarthy EP, Mendu ML, Koo S, Wilhite TJ, et al. Marital status and survival in patients with cancer. J Clin Oncol. 2013;31(31):386976

26. Gouin JP, Kiecolt-Glaser JK. The impact of psychological stress on wound healing: methods and mechanisms. Immunol Allergy Clin North Am. 2011; 31(1):81-93.

\section{Publisher's Note}

Springer Nature remains neutral with regard to jurisdictional claims in published maps and institutional affiliations.

Ready to submit your research? Choose BMC and benefit from:

- fast, convenient online submission

- thorough peer review by experienced researchers in your field

- rapid publication on acceptance

- support for research data, including large and complex data types

- gold Open Access which fosters wider collaboration and increased citations

- maximum visibility for your research: over $100 \mathrm{M}$ website views per year

At BMC, research is always in progress.

Learn more biomedcentral.com/submissions 